\title{
The Influence of Particle Content on the Equi-Biaxial Fatigue Behaviour of Magnetorheological Elastomers
}

\author{
Yanfen Zhou \\ Technological University Dublin, yanfen.zhou@mydit.ie \\ Stephen Jerrams \\ Technological University Dublin, stephen.jerrams@tudublin.ie \\ Tony Betts \\ Technological University Dublin, anthony.betts@tudublin.ie
}

See next page for additional authors

Follow this and additional works at: https://arrow.tudublin.ie/cerart

Part of the Polymer and Organic Materials Commons

\section{Recommended Citation}

Zhou, Y. et al. (2015)The Influence of Particle Content on the Equi-Biaxial Fatigue Behaviour of Magnetorheological Elastomers, Materials and Design 67 (2015) 398-404 . doi:10.1016/

j.matdes.2014.11.056

This Article is brought to you for free and open access by the Centre for Elastomer Research at ARROW@TU Dublin. It has been accepted for inclusion in Articles by an authorized administrator of ARROW@TU Dublin. For more information, please contact arrow.admin@tudublin.ie, aisling.coyne@tudublin.ie,gerard.connolly@tudublin.ie.

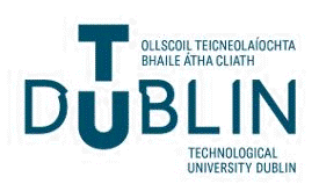




\section{Authors}

Yanfen Zhou, Stephen Jerrams, Tony Betts, Gerald Farrell, and Lin Chen

This article is available at ARROW@TU Dublin: https://arrow.tudublin.ie/cerart/14 


\title{
The influence of particle content on the equi-biaxial fatigue behaviour of magnetorheological elastomers
}

\author{
Yanfen Zhou ${ }^{* a}$, Stephen Jerrams ${ }^{\text {a }}$, Anthony Betts ${ }^{\mathrm{b}}$, Gerald Farrell ${ }^{\mathrm{c}}$, Lin Chen ${ }^{\mathrm{d}}$ \\ ${ }^{a}$ Centre for Elastomer Research, Focas Research Institute, Dublin Institute of Technology, Kevin Street, \\ Dublin 8, Ireland \\ ${ }^{\mathrm{b}}$ Applied Electrochemistry Group, Focas Research Institute, Dublin Institute of Technology, Kevin Street, \\ Dublin 8, Ireland \\ ${ }^{\mathrm{c}}$ Photonics Research Centre, Dublin Institute of Technology, Kevin Street, Dublin 8, Ireland \\ ${ }^{\mathrm{d}}$ Beijing Aeronautical Science and Technology Research Institute, Commercial Aircraft Corporation of \\ China, PR China
}

\begin{abstract}
The equi-biaxial fatigue behaviour of silicone based magnetorheological elastomers (MREs) with various volume fractions of carbonyl iron particles ranging between $15 \%$ and $35 \%$ was studied. Wöhler curves for each material were derived by cycling test samples to failure over a range of stress amplitudes. Changes in complex modulus $\left(\mathrm{E}^{*}\right)$ and dynamic stored energy during the fatigue process were observed. As for other elastic solids, fatigue resistance of MREs with different particle contents was shown to be dependent on the stress amplitudes applied. MREs with low particle content showed the highest fatigue life at high stress amplitudes while MREs with high particle content exhibited the highest fatigue resistance at low stress amplitudes. $\mathrm{E}^{*}$ fell with the accumulation of cycles for each material, but the change was dependent on the particle content and stress amplitude applied. However, each material failed in a range suggesting a limiting value of $\mathrm{E}^{*}$ for the material between 1.22 $\mathrm{MPa}$ and 1.38 MPa regardless of the particle content and the magnitude of the stress amplitude. In keeping with results from previous testing, it was shown that dynamic stored energy can be used to predict the fatigue life of MREs having a wide variation in particle content.
\end{abstract}

Keywords: Magnetorheological elastomers; Equi-biaxial fatigue; Carbonyl iron; Complex modulus; Dynamic stored energy

\section{Introduction}

Magnetorheological elastomers (MREs) consist of micron sized magnetically permeable particles suspended in a non-magnetic elastomeric matrix.Various elastomers can be used as matrices to prepare MREs with different properties [1-4]. Ferromagnetic particles have been reported to have sizes from a few to a few hundred microns [5]. Pure iron is the most widely used magnetizable particle because of its excellent soft magnetic property, high saturation magnetization and spherical shape [6].

The magnetorheological (MR) effect is defined as a reversible change in the viscoelastic properties of an MR material when subjected to a magnetic field. The concentration of magnetic particles has a significant influence on the properties of MREs. Generally, the content of magnetizable particles should be higher than $50 \mathrm{wt} \%$ (about $12.3 \mathrm{vol} \%$ ) in order to obtain a

*Corresponding author. Tel: +353 01 4027919. Email: yanfen.zhou@mydit.ie 
significant MR effect. However, deterioration of the mechanical properties is a key issue that affects the practical application of MREs. From the available literature [7] it appears that the maximum MR effect on composite stiffness is obtained when the filler content is rather high; preferably in the region of $30 \mathrm{vol} \%$. However, high iron concentration leads to the deterioration of mechanical properties and influences the long-term stability of MREs. Due to the field dependent rheological response of MREs, they are interesting candidates for adaptive tuned vibration absorbers, stiffness tuneable mounts and suspensions and variable impedance surfaces [8-12].

Since rubber is used for its high reversible deformability, it is inevitable that rubber components will experience fatigue loading during service. This has subsequently led to a demand for the investigation of fatigue behaviour of rubber components, especially in conditions of multi-axial loading. Some authors proposed the use of maximum principal stretch $\left(\lambda_{\max }\right)$ [13, 14], maximum principal Cauchy stress $\left(t_{\max }\right)$ [15] or strain energy density $(W)[16,17]$ as predictors of rubber fatigue. More recently, several sophisticated multi-axial fatigue life predictors, based on critical plane-based approaches, have been developed for rubbers [18, 19]. However, predictions of the fatigue properties of elastomeric materials and components are still imperfect because of their complex mechanical behaviour, especially for emerging smart materials like MREs.

Previously, the equi-biaxial fatigue behaviour of both isotropic and anisotropic silicone based MREs were initially studied [20,21]. Some preliminary findings which suggested there is a limiting value of complex modulus at failure and that a dynamic stored energy criterion can be used for predicting the fatigue life of MREs were presented. In the research described here, the equi-biaxial fatigue behaviour of silicone based MREs containing different volume fractions of magnetic particles were investigated by using the cyclic bubble inflation method. Physical testing allowed the previous conclusions to be confirmed and also provided insight into the influence of magnetic particle content on the fatigue behaviour of MREs.

\section{Materials and Methods}

\subsection{Materials}

Isotropic silicone rubber (SR) based MREs were fabricated by incorporating different volume fractions $(15 \%, 20 \%, 25 \%, 30 \%$ and $35 \%)$ of soft carbonyl iron $(\mathrm{CI})$ magnetic particles $(\mathrm{d} 50=$ $6.0-7.0 \mu \mathrm{m}, \mathrm{CS}$ grade, BASF) into a two component room temperature vulcanized (RTV) silicone rubber. Firstly, silicone rubber was mixed with a catalyst at a 10:1 ratio, before carbonyl iron particles were introduced to the mixture which was mechanically stirred to distribute the particles evenly in the elastomer matrix. The whole mixture was degassed in a vacuum to remove entrapped air bubbles and then poured into a mould. After further degassing in the mould, the compound was kept at room temperature for 48 hours to allow solidification. The thickness of the fabricated samples was nominally $1 \mathrm{~mm}$.

\subsection{Microstructure observation}

The surface morphologies of MREs with different volume fractions of carbonyl iron particles were observed by using Scanning Electron Microscopy (SEM). The specimens were coated with a $2 \mathrm{~nm}$ gold layer prior to testing in order to improve surface conductivity and SEM images were taken with an accelerating voltage of $5 \mathrm{kV}$. 


\subsection{Equi-biaxial testing}

Equi-biaxial fatigue tests were conducted on each sample by using the bubble inflation system as decsribed in a previous paper [20]. A minimum of three tests were carried out at each stress amplitude.

\section{Results and Discussion}

\subsection{Microstructure analysis}

Figure 1 represents the surface morphologies of MREs containing different volume fractions of carbonyl iron particles. It can be seen that spherically shaped iron particles dispersed randomly in the silicone resin for all test samples. As the filler content increased, the distance between iron particles became proportionally smaller. When the particle content was very high, some agglomeration of particles could be observed.

\subsection{Wöhler curves}

Figure 2 shows the Wöhler (S-N) curves for SR and SR based MREs with different CI contents varying between $15 \%$ and 35\%. Unsurprisingly, irrespective of the carbonyl iron particles content, fatigue life of MREs decreased as stress amplitude increased for a minimum stress of zero. However, the dependence of fatigue life on stress amplitude varied for MREs with different particle content. This can be seen from the slope of S-N curves of each sample which is given in Table 1. It can be noted that the absolute value of the slope of S-N curves decreased as particle content increased. This indicates that the decrease of fatigue life as stress amplitude increased was more rapid for MREs with lower particle contents. It is reasonable to assume that the matrix rubber plays a dominant role in controlling the fatigue of MREs when they contain fewer magnetic particles, e.g. 15\%. However, the fatigue behaviour of MREs is probably more dependent on the particle networks when the magnetic particle content is increased beyond this level. The particle networks are very easily broken down in conditions of high loadings, but exhibit strength at low loadings which consequently lead to higher fatigue lives. Equations for fatigue life prediction, relating life $\left(N_{f}\right)$ to engineering stress amplitudes $\left(\sigma_{a}\right)$ for SR based MREs were derived as follows:

$$
\ln \left(N_{f}\right)=A_{1} \sigma_{a}+A_{2}
$$

where $A_{1}$ and $A_{2}$ are material specific constants dependent on magnetic particle content. The values of $A_{1}$ and $A_{2}$ for MREs with various CI contents are listed in Table 2.

\subsection{Complex Modulus}

It is known that the mechanical response of rubber is not only highly nonlinear but is also characterized by large strains, energy dissipation (mechanical and thermal) and the deterioration of mechanical properties under fatigue loading [22]. Figure 3 depicts the changes in complex modulus $\left(\mathrm{E}^{*}\right)$ during the fatigue process for pure silicone rubber and MREs containing different volume fractions of carbonyl iron particles. It can be seen that, for each material, $\mathrm{E}^{*}$ decreased as cycles accumulated due to stress softening induced by the cyclic loading. Significant reductions 
in modulus can be observed in the initial cycles $(<10)$. The increase in hysteresis with increase in stress amplitude can be observed from the first stress-strain cycles at stress amplitudes of $1 \mathrm{MPa}$, $0.875 \mathrm{MPa}, 0.75 \mathrm{MPa}$ and $0.625 \mathrm{MPa}$ as shown in Figure 4.

The higher the magnetic particle content in an MRE then the higher will be the elastic modulus. This is to be expected since the incorporation of rigid fillers typically increases the stiffness of an elastomeric material due to the hydrodynamic reinforcement.

It is also worth noting that although the reductions in modulus were most significant in the first few cycles for MREs with lower particle contents, the rate of reduction was less when the samples were close to failure. However, for MREs with higher particle contents (30\% and 35\%), $\mathrm{E}^{*}$ decreased gradually with the accumulation of cycles and the materials subsequently failed after a rapid drop of $\mathrm{E}^{*}$ in the last few cycles. To assist in understanding this behaviour, stressstrain relations for MREs with 20\% and 30\% carbonyl iron particles during fatigue tests at a stress amplitude of $0.75 \mathrm{MPa}$ are presented in Figure 5. It can be noted that both the samples failed after about 1400 cycles but they exhibited quite different stress-strain behaviour throughout the fatigue process. For MRE samples with $20 \%$ carbonyl iron particles, stress softening was most pronounced in the first dozens cycles and became insignificant afterwards. However, for MREs containing 30\% carbonyl iron particles, the stress-strain curves altered little in the first 100 cycles and large deformation occurred predominately in the last few cycles before failure.

It is known that the total life of a rubber component subjected to fatigue loading comprises three stages: crack nucleation, crack propagation and rapid failure [23]. Crack nucleation plays a very important role in determining the fatigue life because the presence of a crack damages the structural integrity of a component and the hyperelastic field surrounding the crack offers little resistance to its growth [24]. During the fatigue tests on MREs, the cyclic loading induced continuous damage to the filler networks which invariably resulted in a drop in $\mathrm{E}^{*}$. For MREs containing fewer particles, after the filler networks were broken down, the matrix rubber reacted to the loading producing large deformation, so the material eventually failed at a life dependent on the stress amplitudes applied. However, for MREs with higher particle contents, the breakdown of particle agglomerates and the debonding of particles from matrices induced high levels of crack nucleation and cavitation in the matrix rubber. This deterioration in the matrix material led to a diminished ability to resist external loading. As of result, the samples underwent sudden failures after material specific drops in $\mathrm{E}^{*}$.

Nonetheless, for each MRE sample tested, it was found that fatigue failure took place at a limiting value of $\mathrm{E}^{*}$ regardless of the stress amplitudes applied. As can be seen from Table 3, these values are very similar for each CI content and are generally lower than the measured values of $\mathrm{E}^{*}$ at failure for pure silicone rubber. It suggests that the weakening of the rubber matrix is the controlling parameter in respect of complex modulus at fatigue failure. However, the dissimilarity of the limiting value of $\mathrm{E}^{*}$ for pure silicone rubber and MREs as well as the dependence of changes in $\mathrm{E}^{*}$ on carbonyl iron content during the fatigue process indicate that separation and crack initiation at interfacial layers has a great influence on the fatigue process of MREs.

\subsection{Strain energy density}


The evolution of stored energy density with the accumulation of cycles for MREs with different CI contents is depicted in Figure 6. For each sample, the stored energy density increased with the increase in cyclesat a constant stress amplitude. However, the change of stored energy density during the entire fatigue process differed for MREs with various particle contents. It can be seen that the stored energy density increased significantly in the first few cycles and became stable for MREs with lower carbonyl iron contents (15\%, 20\% and 25\%). However,dependent on stress amplitude, for high particle contents (30\% and 35\%) dynamic stored energy remained virtually unchanged in the first few cycles and increased rapidly in the last few cycles before material failure. As for the observed changes in complex modulus, they could be attributed to quite different fatgiue mechanism for each material.

As shown in Figure 7 , when plotted against $\log _{10}$ cycles to failure, the stored energy density at failure for a range of stress amplitudes was found to decrease linearly regardless of the particle content.This indicates that the stored energy criterion can be used as a plausible fatigue life predictor for isotropic SR based MREs irrespective of the magnetic particle content and the stress amplitudes applied.A stored energy density based equation for fatigue life prediction can be written by relating life $\left(N_{f}\right)$ to stored energy $\left.\left(W_{s}\right)\right)$ as shown:

$$
\ln \left(N_{f}\right)=B_{1} W_{s}+B_{2}
$$

where $B_{1}$ and $B_{2}$ are material specific constants dependent on the magnetic particle content. The values for $B_{1}$ and $B_{2}$ for MREs with various CI content are given in Table 4.

\section{Conclusions}

Isotropic silicone based MREs with various carbonyl iron contents were fabricated and their equi-biaxial fatigue behaviour was investigated. S-N curves for MREs with a range of carbonyl iron contents from $15 \%$ to $35 \%$ were produced. The absolute value of the slope of S-N curves was found to decrease as particle content increased. This indicates that the decrease of fatigue life as stress amplitude increased was more rapid for MREs with lower particle contents whereas it was more gradual for MREs with higher particle contents.

Physical changes which are characterized by complex modulus $\left(\mathrm{E}^{*}\right)$ during the fatigue process were also studied for MREs with different particle contents. It was shown that for each material, $\mathrm{E}^{*}$ decreased as cycles accumulated. Tests at lower stress amplitudes generally exhibited longer times for stress softening to reach a minimum. For the same loading conditions, MREs with lower particle content failed after $\mathrm{E}^{*}$ had stabilized while MREs containing more particles failed after a rapid drop in $\mathrm{E}^{*}$ just prior to failure. However, for each material tested, fatigue failure took place at a limiting value of $\mathrm{E}^{*}$ between $1.22 \mathrm{MPa}$ and $1.38 \mathrm{MPa}$ regardless of the particle content and the stress amplitudes applied.

Dynamic stored energy was found to increase with the accumulation of cycles for each material tested over a range of stress amplitudes. When plotted against cycles to failure, dynamic stored energy was found to decrease linearly, which indicates that dynamic stored energy can be used as a plausible predictor in determining the fatigue life of MREs irrespective of particle content. This further strengthens our previous conclusion that dynamic stored energy can be used as a reliable predictor in determining the fatigue life of isotropic and anisotropic MREs with $20 \%$ magnetic particles [25]. Equations relating fatigue life to stress amplitude and dynamic stored energy were 
derived and the parameters obtained are feasible for use in FEA modelling which will allow the complex dynamic mechanical behaviour of MREs to be studied.

\section{Acknowledgements}

The authors would like to give thanks for the financial support from the Irish Research Council (Science, Engineering and Technology, IRCSET) and the use of facilities in the Focas Research Institute, Dublin Institute of Technology.

\section{References}

[1] von Lockette PR, Lofland SE, Koo JH, Kadlowec J, Dermond M. Dynamic characterization of bimodal particle mixtures in silicone rubber magnetorheological materials. Polymer Testing 2008; 27:931-935.

[2] Chen L, Gong XL, Jiang WQ, Yao JJ, Xia HX, Li WH. Investigation on magnetorheological elastomers based on natural rubber. Journal of Materials Science 2007; 42:5483-5489.

[3] $\mathrm{Hu}$ Y, Wang YL, Gong XL, Gong XQ, Zhang XZ, Jiang WQ, Zhang PQ,Chen ZY. New magnetorheological elastomers based on polyurethane/Si-rubber hybrid. Polymer Testing 2005; 24:324-329.

[4] Boczkowska A, Awietjan SF. Smart composites of urethane elastomers with carbonyl iron. Journal of Materials Science 2009; 44:4104-4111.

[5] Lokander M, Stenberg B. 2003 Improving themagnetorheological effect in isotropic magnetorheologicalrubber materials. Polymer Testing 2003; 22:677-680.

[6] Lu X, Li M, Yang K, Xie H, Yin Q, Wang D. SEBS Based Magnetorheological Elastomer: Preparation and Property. 2011.

[7] Davis L. Model of magnetorheological elastomers.Journal of Applied Physics 1999; 85:33483351.

[8] Elie LD, Ginder JM, Nichols ME, Stewart WM. Method and apparatus for reducing brake shudder. US Patents, 1998.

[9] Watson JR. Method and apparatus for varying the stiffness of a suspension bushing.US Patents, 1997.

[10] Elie LD, Ginder JM, Mark JS, Nichols ME, Stewart WM. Method for allowing rapid evaluation of chassis elastomeric devices in motor vehicles. US Patents, 1999.

[11] Fuchs A, Gordaninejad F, Hitchcock GH. Controllable magneto-rheological elastomer vibration isolator. US Patents, 2006.

[12] Hoang N, Zhang N, Du H. A dynamic absorber with a soft magnetorheological elastomer for powertrain vibration suppression. Smart Mater. Struct. 2009; 18:074009.

[13] Cadwell SM, Merrill RA, Sloman CM, Yost FL. Dynamic fatigue life of rubber. Rubber cChemistry and Technology 1940; 13:304-315.

[14] Fielding JH. Flex life and crystallization of synthetic rubber, Industrial and Engineering Chemistry, 1943, 35, 1259-1261.

[15] Saintier N, André N, Cailletaud G, Piques R. Crack nucleation and propagation under multi-axial fatigue in natural rubber. International Journal of Fatigue 2006; 28: 61-72.

[16] Gent AN, Lindley PB, Thomas AG. Cut growth and fatigue of rubbers. I. The relationship between cut growth and fatigue. Journal of Applied Polymer Science 1964; 8:455-466. 
[17] Roberts BJ, Benzies JB. The relationship between unixial and equi-biaxial fatigue in gum and carbon black filled vulcanizates. Proceedings of Rubbercon1977; 2.1: 2.1-2.13.

[18] Mars WV. Cracking energy density as a predictor of fatigue life under multiaxial conditions. Rubber ChemTechnol 2002; 75:1-17.

[19] Ayoub G, Nait-Abdelaziz M, Zairi F, Gloaguen JM, Charrier P. Fatigue life prediction of rubber-like materials under multiaxial loading using a continuum damage mechanism approach: effects of two-blocks loading and $\mathrm{R}$ ratio. Mech Mater 2012 52: 87-102.

[20] Zhou YF, Jerrams S, Chen L. Multi-axial fatigue in magnetorheological elastomers using bubble inflation, Materials and Design 2013; 50: 68-71.

[21] Zhou YF, Jerrams S, Betts A, Chen L. The effect of microstructure on the dynamic equibiaxial fatigue behaviour of magnetorheological elastomers. $8^{\text {th }}$ European Conference on Constitutive Model for Rubber (ECCMR VIII), 25-28 June, 2013, San Sebastian, Spain.

[22] Ayoub G, Zaïri F, Naiit-Abdelaziz M, Gloaguen JM. Modeling the low-cyclefatigue behaviour of visco-hyperelastic elastomeric materials using a newnetwork alteration theory: application to styrene-butadiene rubber. J MechPhys Solids 2011; 59:473-495.

[23] Mars WV, Fatemi A. Fatigue crack nucleation and growth in filled natural rubber. Fatigue FractEng Mater Struct 2003; 26:779-789.

[24] Ayoub G, Naït-Abdelaziz M,Zaïri F. Multiaxial fatigue life predictors for rubber: Application of recent developments to a carbon-filled SBR. International Journal of Fatigue 2014; 66:168-176.

[25] Zhou YF, Jerrams S, Betts A, ChenL.Fatigue life prediction of magnetorheological elastomers subjected to dynamic equi-biaxial cyclic loading. Materials Chemistry and Physics 2014; 146: 487-492. 


\section{List of figures}

Figure 1 Surface morphologies of MREs containing different volume fraction of CI: (a) 15\%; (b) $20 \%$; (c) $25 \%$; (d) $30 \%$; (e) $35 \%$

Figure 2Wöhler curves for SR and SR based MREs with different CI content

Figure 3 Changes in $\mathrm{E}^{*}$ during the fatigue process for pure SR (a) and MREs containing different volume fractions of CI: (b) $15 \%$; (c) $20 \%$; (d) $25 \%$; (e) $30 \%$; (f) $35 \%$

Figure 4 Stress-strain curves for the first cycle induced by different stress amplitudes $(\mathrm{CI}=15 \%)$ Figure 5 Stress-strain curves for SR based MREs with $20 \%$ and $30 \%$ CI during a fatigue test at $\sigma_{\mathrm{a}}=0.75 \mathrm{MPa}$

Figure 6 Evolution of stored energy against cycles for MREs with different CI contents: (a) 15\%; (b) $20 \%$; (c) $25 \%$; (d) $30 \%$; (e) $35 \%$

Figure 7Plots of stored energy density at failure versus $\log _{10}$ cycles at failure for isotropic SR based MREs with different CI content: (a) 15\%; (b) 20\%; (c) 25\%; (d) 30\%; (e) $35 \%$
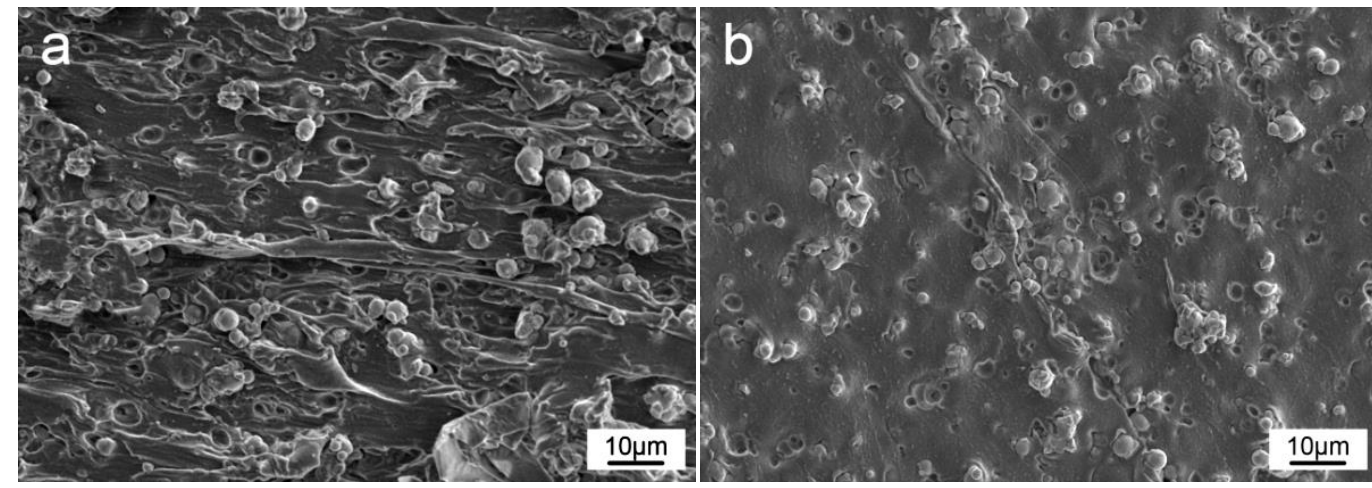

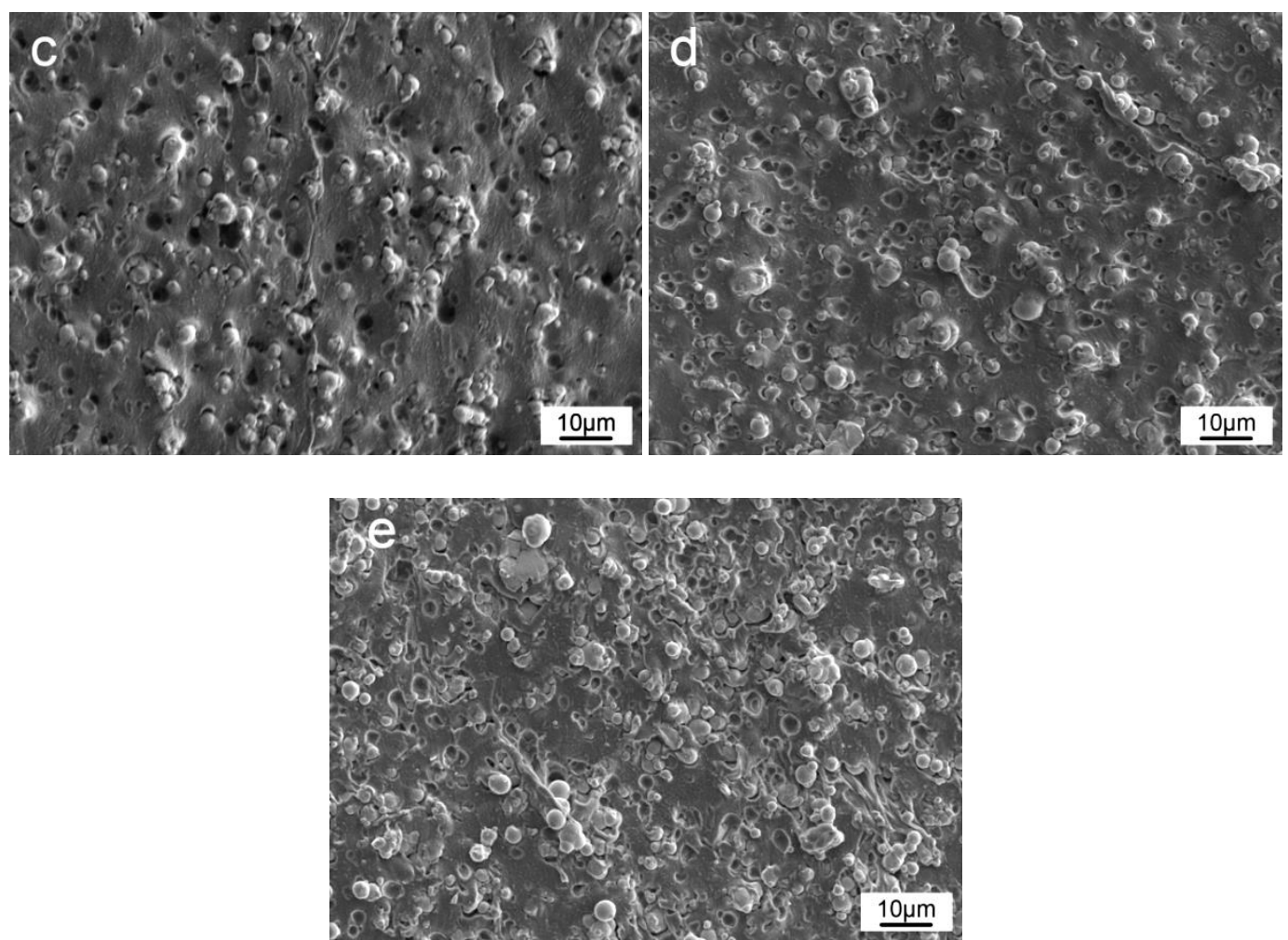

Figure 1 Surface morphologies of MREs containing different volume fraction of CI: (a) 15\%; (b) $20 \%$; (c) $25 \%$; (d) $30 \%$; (e) $35 \%$

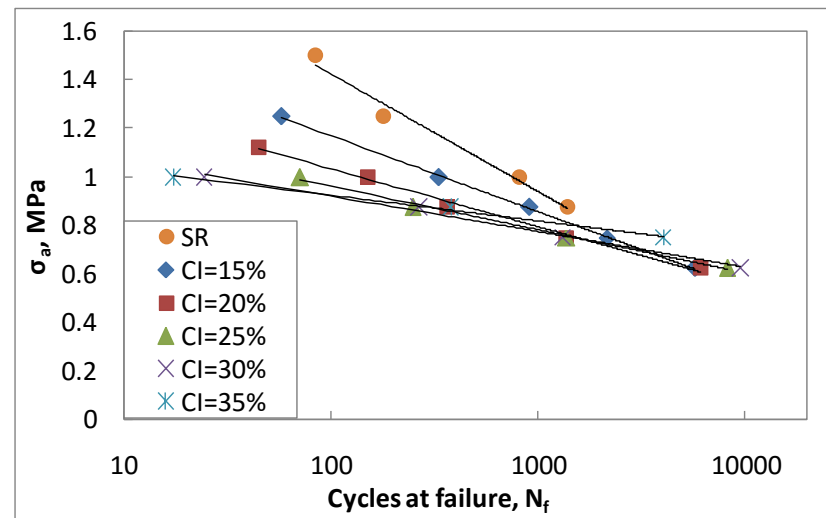

Figure 2 Wöhler curves for SR and SR based MREs with different CI content
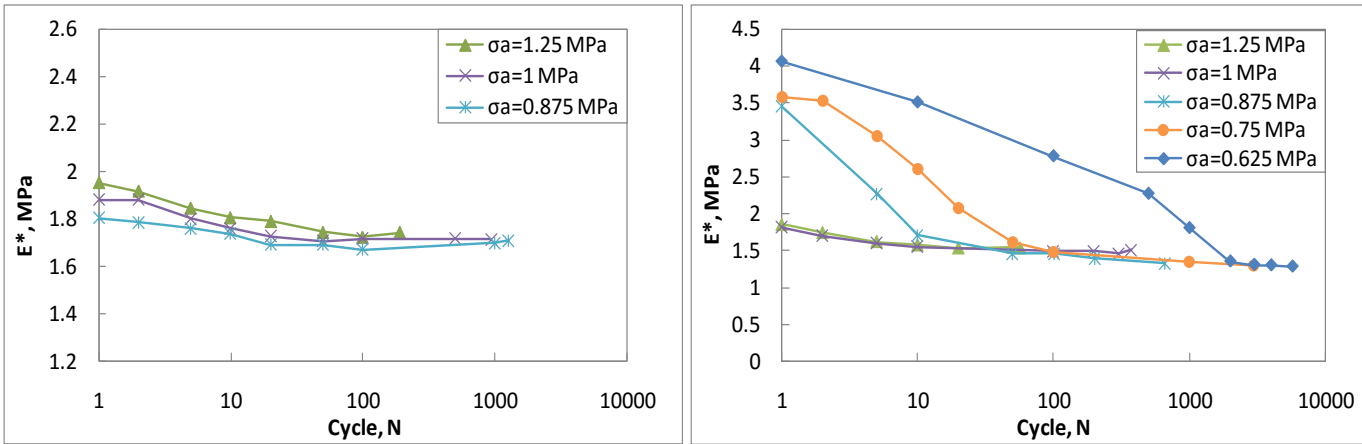
(a)

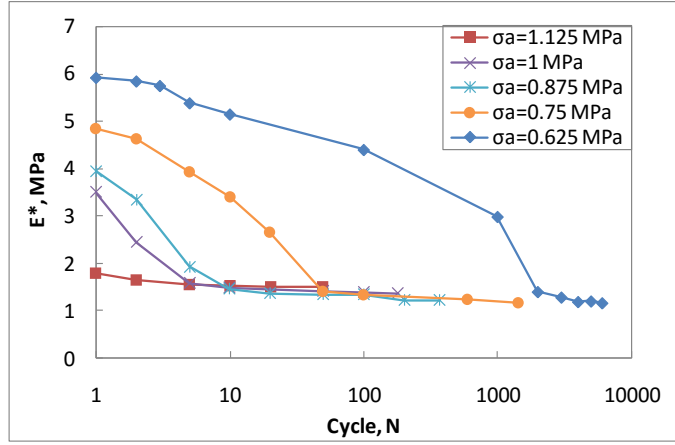

(c)

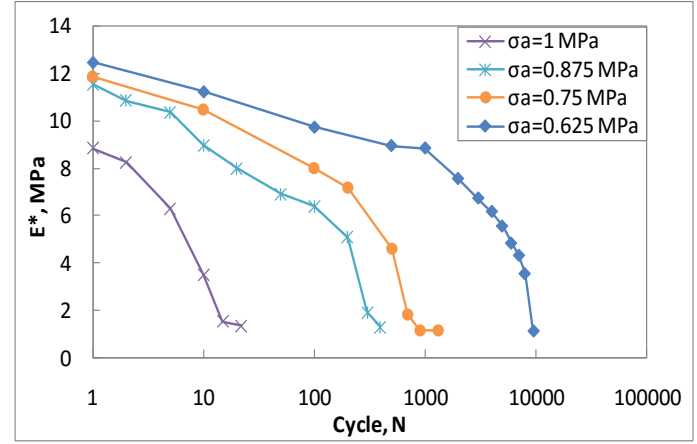

(e) (b)

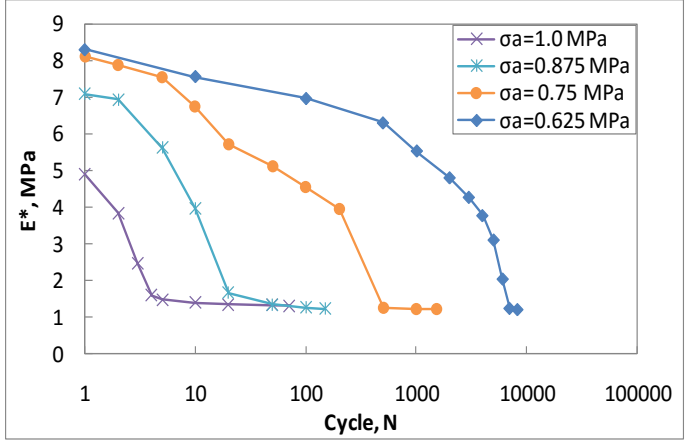

(d)

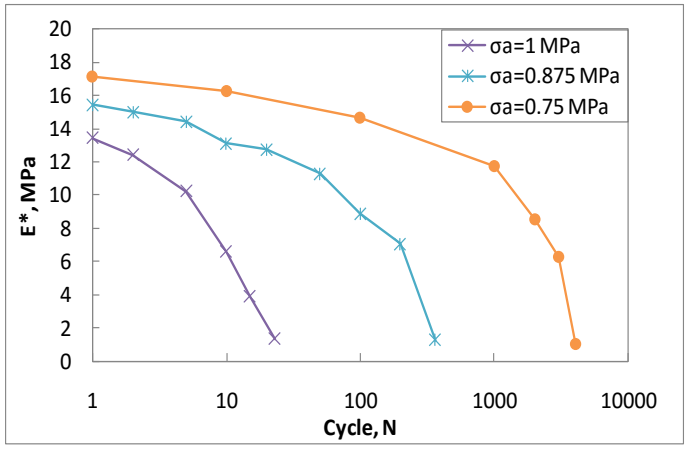

(f)

Figure 3 Changes in $\mathrm{E}^{*}$ during the fatigue process for pure SR (a) and MREs containing different volume fractions of CI: (b) $15 \%$; (c) $20 \%$; (d) $25 \%$; (e) $30 \%$; (f) $35 \%$

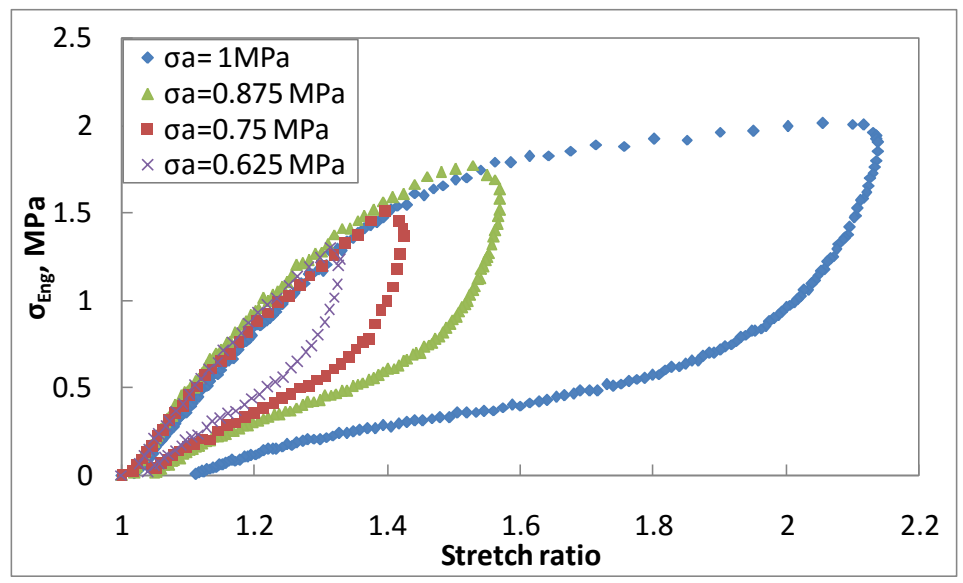

Figure 4 Stress-strain curves for the first cycle induced by different stress amplitudes (CI=15\%) 


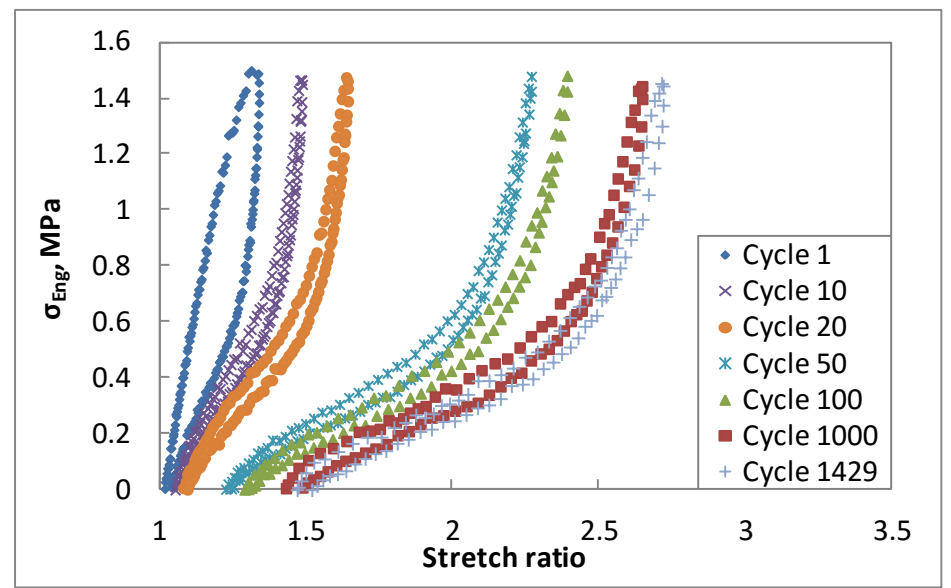

(a) $20 \%$ CI, sample failed at 1430 cycles

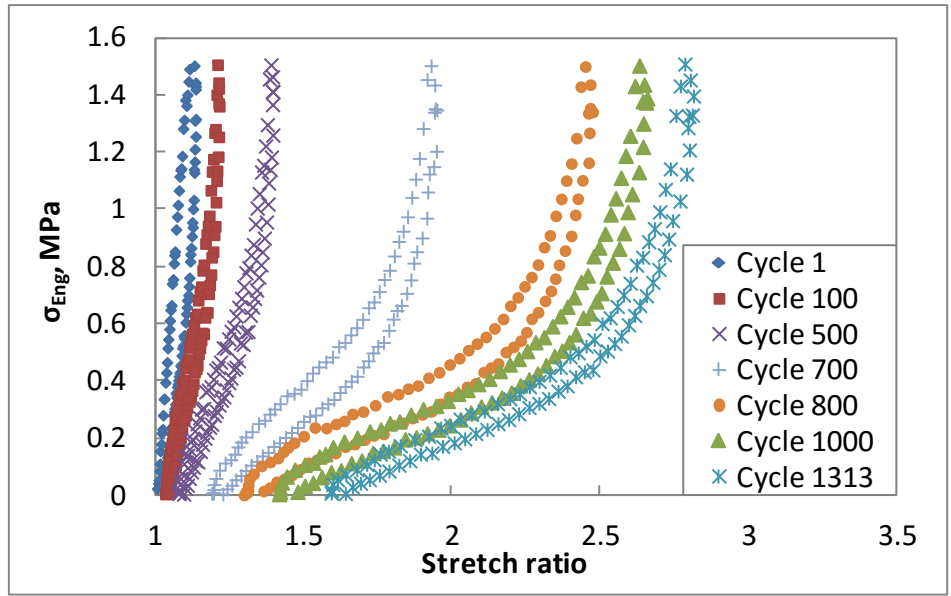

(b) $30 \% \mathrm{CI}$, sample failed at 1314 cycles

Figure 5 Stress-strain curves for SR based MREs with 20\% and 30\% CI during a fatigue test at $\sigma_{\mathrm{a}}=0.75 \mathrm{MPa}$

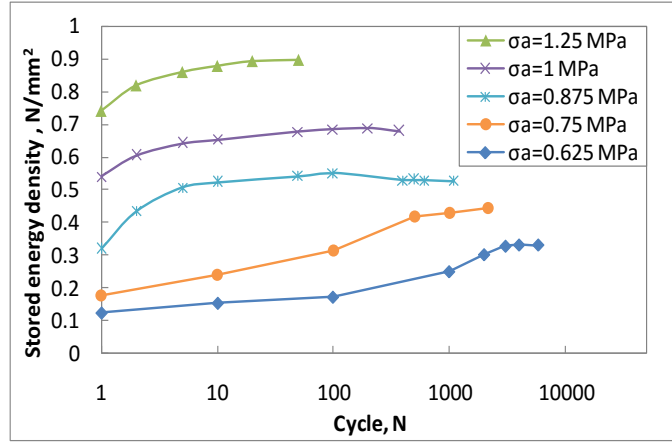

(a)

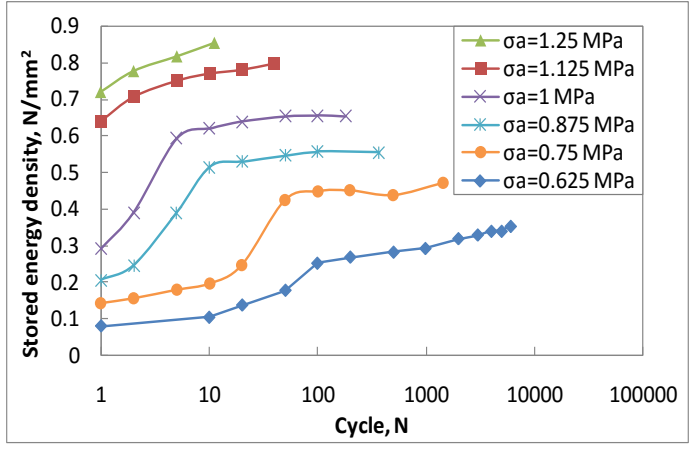

(b) 


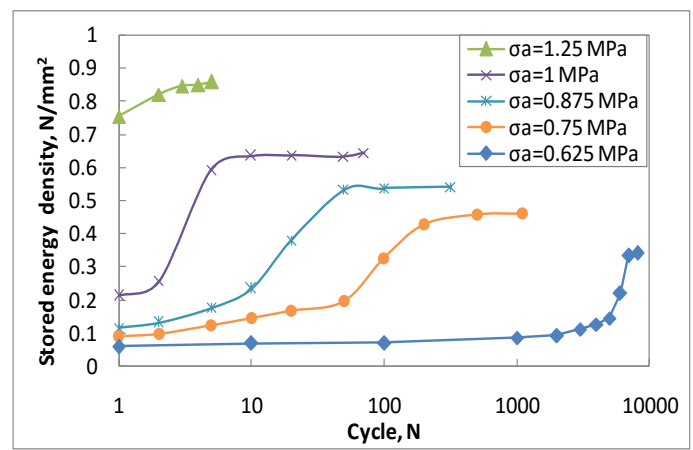

(c)

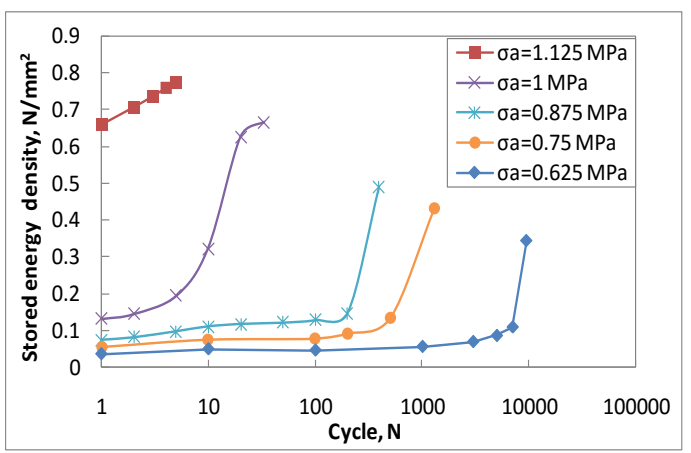

(d)

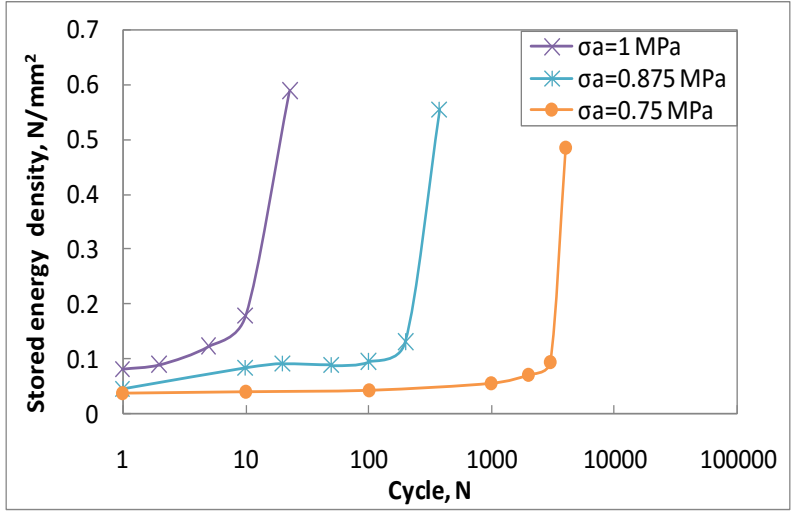

(e)

Figure 6 Evolution of stored energy against cycles for MREs with different CI contents: (a) 15\%;

(b) $20 \%$; (c) $25 \%$; (d) $30 \%$; (e) $35 \%$

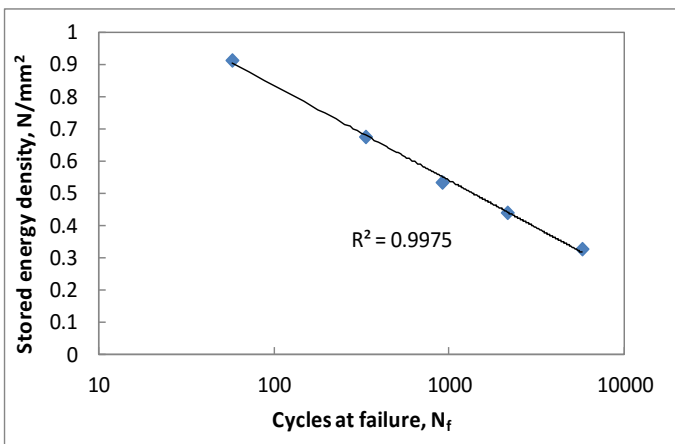

(a)

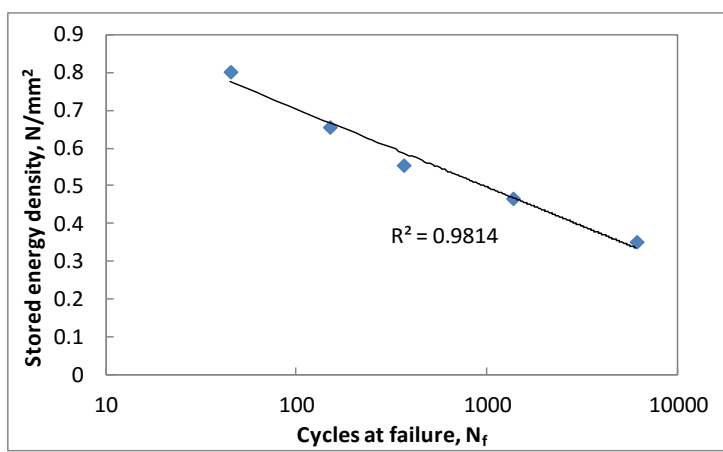

(b) 


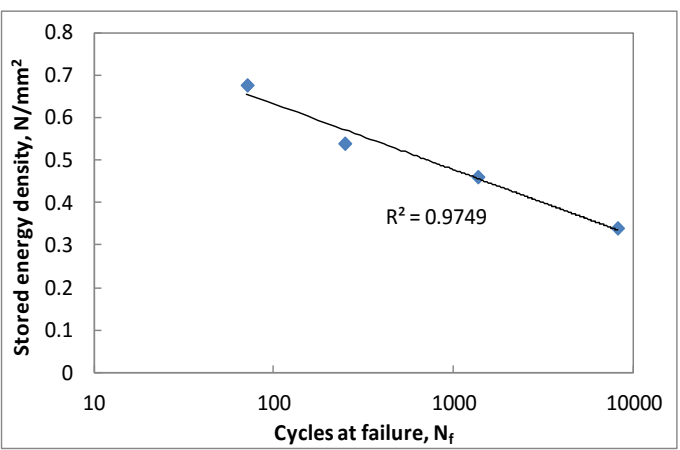

(c)

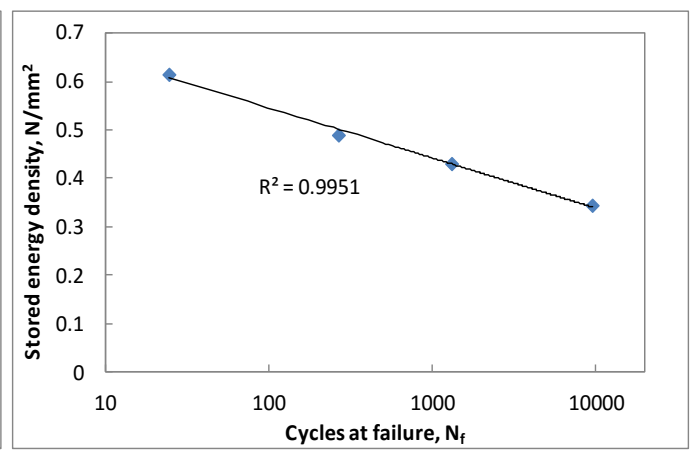

(d)

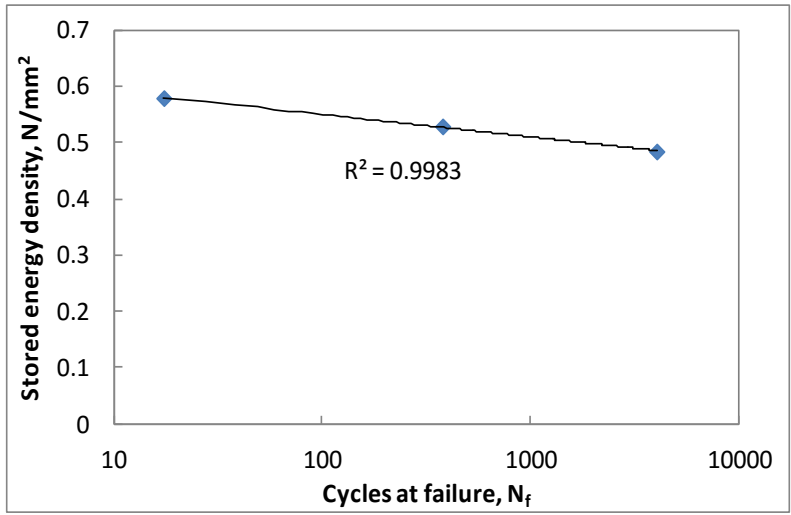

(e)

Figure 7 Plots of stored energy density at failure versus $\log _{10}$ cycles at failure for isotropic SR based MREs with different CI content: (a) 15\%; (b) 20\%; (c) 25\%; (d) 30\%; (e) $35 \%$ 


\section{List of Tables}

Table 1 The slope of S-N curves for each sample set

Table 2 Values for $A_{1}$ and $A_{2}$ for a series of MREs with different CI content

Table $3 \mathrm{E}^{*}$ at failure for MREs with different CI content

Table 4 Values for $B_{1}$ and $B_{2}$ for a series of MREs with different CI content 
Table 1 The slope of S-N curves of each sample

\begin{tabular}{cc}
\hline CI content & Slope \\
\hline $15 \%$ & -0.1358 \\
$20 \%$ & -0.1031 \\
$25 \%$ & -0.0779 \\
$30 \%$ & -0.0638 \\
$35 \%$ & -0.0456 \\
\hline
\end{tabular}

Table 2 Values for $A_{1}$ and $A_{2}$ for a series of MREs with different CI content

\begin{tabular}{ccc}
\hline CI content & $\boldsymbol{A}_{\boldsymbol{I}}\left(\mathbf{m m}^{2} / \mathbf{N}\right)$ & $\boldsymbol{A}_{2}$ (no units) \\
\hline $15 \%$ & -0.1358 & 1.7961 \\
$20 \%$ & -0.1031 & 1.5071 \\
$25 \%$ & -0.0779 & 1.3191 \\
$30 \%$ & -0.0638 & 1.2132 \\
$35 \%$ & -0.0456 & 1.1348 \\
\hline
\end{tabular}

Table $3 \mathrm{E}^{*}$ at failure of MREs with different CI contents

\begin{tabular}{cc}
\hline CI contents & $\mathbf{E}^{*}(\mathbf{M P a})$ \\
\hline $0 \%$ & $1.75 \pm 6.58 \%$ \\
$15 \%$ & $1.38 \pm 8.19 \%$ \\
$20 \%$ & $1.32 \pm 10.05 \%$ \\
$25 \%$ & $1.26 \pm 8.12 \%$ \\
$30 \%$ & $1.24 \pm 6.84 \%$ \\
$35 \%$ & $1.22 \pm 9.13 \%$ \\
\hline
\end{tabular}


Table 4 Values for $B_{1}$ and $B_{2}$ for a series of MREs with different CI content

\begin{tabular}{ccc}
\hline CI content & $\boldsymbol{B}_{\boldsymbol{1}}\left(\mathbf{m m}^{2} / \mathbf{N}\right)$ & $\boldsymbol{B}_{2}$ (no units) \\
\hline $15 \%$ & -0.1282 & 1.4262 \\
$20 \%$ & -0.0898 & 1.1168 \\
$25 \%$ & -0.0676 & 0.9449 \\
$30 \%$ & -0.0448 & 0.7519 \\
$35 \%$ & -0.0174 & 0.6306 \\
\hline
\end{tabular}

